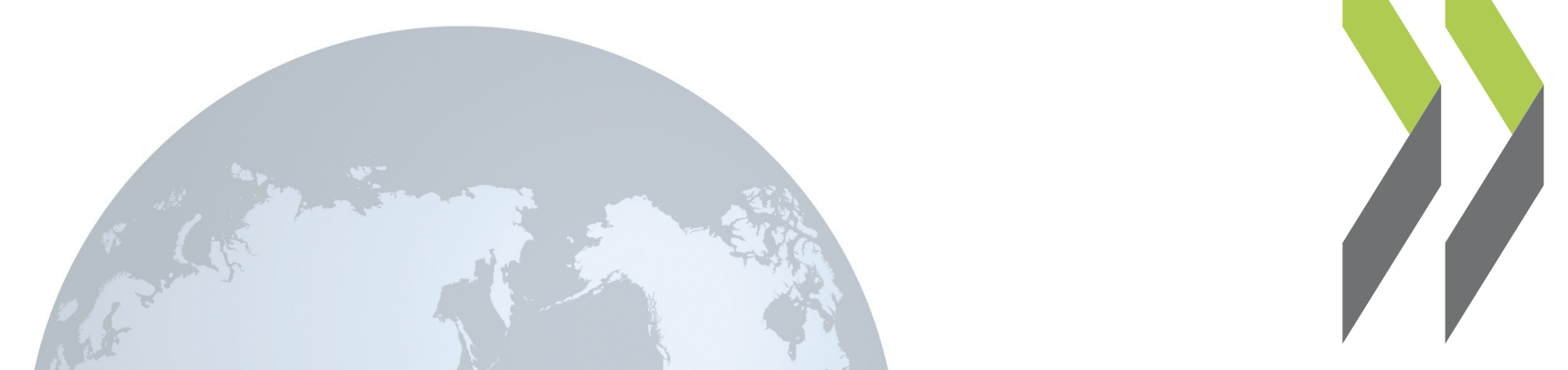

OECD Regional Development Working Papers 2013/10

\author{
Growth Trends \\ and Characteristics \\ of OECD Rural Regions
}

Enrique Garcilazo 


\section{OECD REGIONAL DEVELOPMENT WORKING PAPERS}

This series is designed to make available to a wider readership selected studies on regional development issues prepared for use within the OECD. Authorship is usually collective, but principal authors are named. The papers are generally available only in their original language English or French with a summary in the other if available.

The opinions expressed in these papers are the sole responsibility of the author(s) and do not necessarily reflect those of the OECD or the governments of its member countries.

Comment on the series is welcome, and should be sent to either gov.contact@oecd.org or the Public Governance and Territorial Development Directorate, 2, rue André Pascal, 75775 PARIS CEDEX 16, France.

OECD Regional Development Working Papers are published on http://www.oecd.org/gov/regional/workingpapers

Applications for permission to reproduce or translate all or part of this material should be made to: OECD Publishing, rights@oecd.org or by fax 33145249930.

(C) OECD 2013 


\title{
GROWTH TRENDS AND CHARACTERISTICS OF OECD RURAL REGIONS
}

\author{
Enrique Garcilazo \\ Public Governance and Territorial Development Directorate, OECD
}

This paper benchmarks the performance of OECD rural regions with other types of OECD regions over the period 1995-2010. OECD regions are classified into three types according to the OECD regional typology and into four types according to the extended OECD typology. The latter classifies rural regions into rural regions close to cities and rural remote regions. The analysis focuses on two time-periods: the first prior to the global financial crisis covering 1995 to 2007 and the second capturing the effects of the crisis from 2007-2010. The results display a relative stable trend in settlement patterns among urban and rural regions over the last 15 years. Level comparisons reveal important differences between urban and rural regions. The latter are characterised with low density, long distances and lack of critical mass in comparison to other OECD regions. Notable differences are also present within rural regions. In terms of performance, rural regions record the highest average growth in GDP per capita and in productivity but also the highest volatility in growth rates during the pre-crises period. Within countries, rural regions record the fastest rate of growth in GDP per capita in $40 \%$ of OECD countries considered. Among rural regions, those close to a city are the most dynamic in GDP per capita, productivity and population growth during 1995-2007. The effects of the crisis have been more severe in urban regions in GDP, GDP per-capita and employment rates. Rural regions in contrast have suffered a higher increase in unemployment rates. Overall the effects of the crisis will likely have a more lasting effect on rural regions, particularly in remote rural regions, due to their thinner and less diversified economic base. In sum this paper finds stark difference between rural and urban regions and between rural regions close to cities and remote rural regions which suggests the need for a differentiated policy approach capable of addressing the different types of challenge.

\section{JEL Classification: R11, O18, P25}

Keywords: Rural development, convergence, impact of global financial crisis, growth and volatility 


\section{TABLE OF CONTENTS}

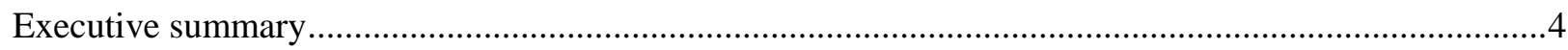

1. Introduction:

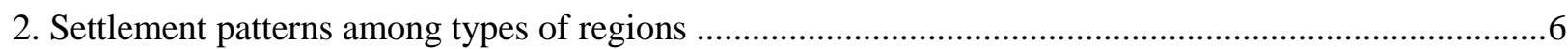

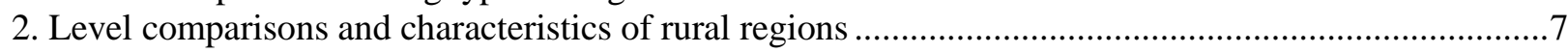

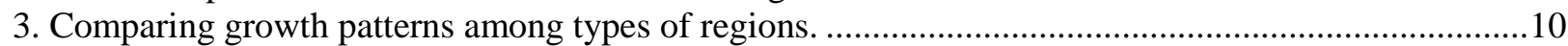

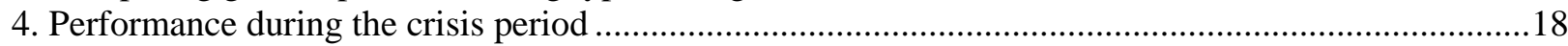

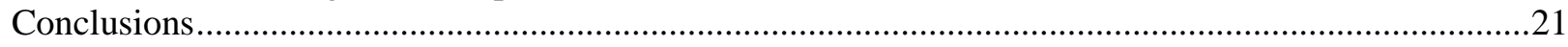

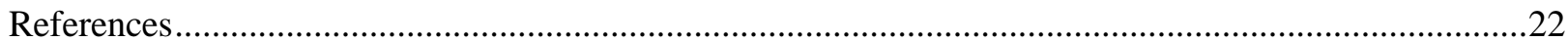

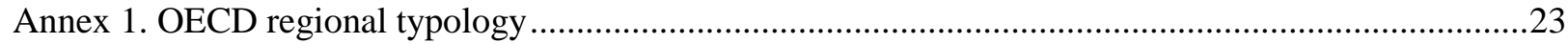

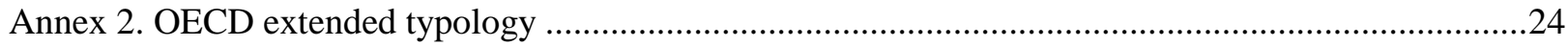

\section{Tables}

Table 1. Population and surface area in OECD TL3 regions, OECD typology, 1995-2010 _...............6

Table 2. Population and surface area in OECD TL3 regions, OECD extended typology, 1995-2010 ..6

Table 3. Average and median levels in OECD TL3 regions, OECD typology, 2009 ...........................

Table 4. Average and median levels in OECD TL3 regions, OECD typology, 2009 …......................9

Table 5. Growth rates among OECD TL3 typology, 1995-2007 …...............................................11

Table 6. Growth rates among OECD TL3 extended typology, 1995-2007 ......................................12

Table 7. Growth rates among OECD TL3 typology within countries, 1995-2007 …........................14

Table 8. Growth rates among OECD TL3 extended typology within countries, 1995-2007 ..............15

Table 9. Effects of the crisis among types of OECD regions, OECD typology 2007-2009...............18

Table 10. Effects of the crisis among types of OECD regions, extended OECD typology 2007-2009.18

\section{Figures}

Figure 1. Distribution of GDP per capita and productivity growth by TL3 typology, 1995-2007........12

Figure 2. Distribution of GDP per capita and productivity growth by TL3 extended typology,

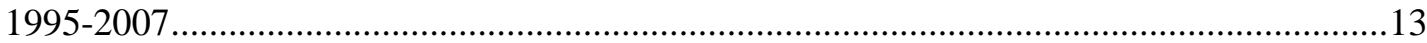

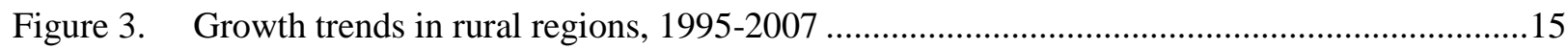

Figure 4. Growth trends in intermediate regions, 1995-2007 ......................................................16

Figure 5. Growth trends in urban regions, 1995-2007..................................................................16

Figure 6. GDP per capita growth and population growth in OECD, 1995-2007 extended typology ....17

Figure 7. Effects of the crisis in GDP per capita in OECD TL3 regions, extended typology,

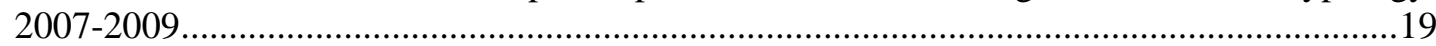

Figure 8. Effects of the crisis in unemployment rate in OECD TL3 regions, extended typology,

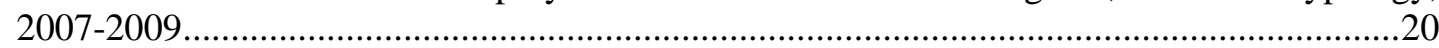

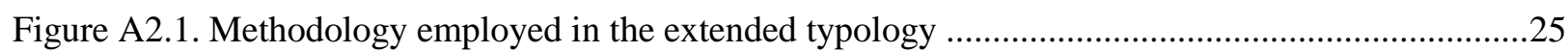




\section{Executive summary}

The publication "The New Rural Paradigm" in 2006 established two key stylised facts that are now the building blocks for modern rural policies in OECD countries. The first highlights that rural is no longer synonymous with agriculture and second that rural is not synonymous with decline. Moreover rural regions can indeed be very productive geographic units with sustainable growth rates. This paper further elaborates and expands the analysis in OECD rural regions using data from a longer time series, a broader number of indicators and applies the refined OECD extended typology which differentiates rural regions into two types: rural regions close to cities and rural remote regions.

The paper is structured around four analytical sections. The first compares settlement patterns among types of regions. The second compares size and scale effects, agglomeration effects, labour market outcomes, competitiveness and innovative activity among types of regions. The third compares growth rates in GDP, GDP per capita, productivity and population and the final section focuses on the effects of the crisis.

The key findings of the first section reveal that more than half of the OECD population live in nonurban regions (25\% in rural and $28 \%$ in intermediate) and the proportion has remained fairly stable and unchanged over a 15 year period covering 1995-2010. The great majority of rural dwellers live in rural regions close to cities (77\%); the remaining $13 \%$ live in rural remote regions.

The second analytical section confirms a number of well known regularities: Urban regions have indeed a significantly larger economic base and enjoy from larger scale effects. On average they produce five times more output than rural regions and they have three times more total employees in their labour force than rural regions. Agglomeration effects are also significantly higher in urban than in rural regions. They tend to be 41 time higher in terms of GDP density and 32 times higher in terms of population density. In terms of inventing activity, it is 10 times higher in urban regions than in rural regions in total patent applications and two and a half time higher in patent intensity. Finally urban regions also enjoy from better labour market matching reflected by lower unemployment rates despite having lower rates of participation and lower employment rates than rural and intermediate regions. These effects yield higher levels of GDP per capita and higher levels of productivity in urban regions vis-à-vis rural regions: the former is $40 \%$ higher in urban regions and the latter is $32 \%$ higher. As always these averages mask considerable variability across urban and rural regions, both across OECD countries and within countries.

The third section reveals that rural regions record the highest average rate of growth in GDP per capita and in productivity over 1995-2007; whereas urban regions display higher overall GDP and population growth. Rural regions close to a city are the most dynamic types of regions in terms of GDP per capita growth and productivity growth and rural remote regions record the second highest growth rate in GDP per capita. In terms of population growth, rural regions close to cities are important attractors of population and rural remote regions are the only type of region suffering from population decline. Rural regions are nevertheless more volatile in their growth performance, both in terms of GDP per capita and in productivity growth. The analysis also finds that rural regions have entered into a process of convergence as well as intermediate regions. In both types of regions there is no signs of agglomeration forces as opposed to urban regions which display both convergence and agglomeration forces.

The final section measuring the effects of the crisis reveals that urban regions suffered the biggest impact over the crisis in terms of total output, per-capita GDP and employment rates. In terms of unemployment rates, rural regions have suffered the largest impact in their labour markets. Amongst rural regions, remote rural regions have been particularly hit; these types of regions suffered the second largest absolute decline in GDP, the largest increase in unemployment rates and the largest decline in employment 
rates. The effects of the crisis will likely have a more lasting effect in rural regions (particularly remote rural regions) given their thinner and less diversified economic base.

In sum this paper finds stark difference between rural and urban regions and between rural regions close to cities and remote rural regions which suggests the need for a differentiated policy approach capable of addressing the different types of challenge.

\section{Introduction:}

Recent OECD analysis measuring the performance of regions reveals the great degree of heterogeneity that exists among OECD regions in their growth performance (OECD 2009a; 2009b; 2012). These studies show that there is no unique pattern for growth. Indeed growth can come in different ways among different types of regions. The evidence reveals that on the one hand there are many predominantly urban regions (urban from now on) outperforming predominantly rural (rural from now on) regions, but on the other hand there are a plentiful of rural regions outperforming urban regions Agglomeration forces and density appear to be neither a necessary nor a sufficient condition to ensure sustainable growth regions at the regional scale.

The factors influencing regional growth can be influenced by a combination of forces operating at different geographic scales: region-specific, nation-wide and global-wide forces.

- Global-wide forces can have a strong influence on all regions as observed during the recent global financial crisis; having a strong negative effect in the performance of all OECD regions.

- At the national scale, factors common to all regions in a given country will have an impact on all regions from the country. For instance growth will tend to be higher in all regions of a country at the peak of its business cycle than in a country in recession; sound macroeconomic policies will result in faster regional growth and exchange rate policies are also critical drivers.

- Region-wide forces play an important role resulting from a combination of interconnected factors among others human capital and skills, infrastructure, capacity to innovate, geography, amenities in a region, functioning of local labour markets, industry specialisation, as well as institutional and policy factors operating at the regional level (OECD 2009a, 2009b, 2012). These regional factors vary from region to region, reflecting the fact that each region is unique.

The analysis in the paper focuses on rural regions. The aim is to expand our understanding on the growth trends and characteristics of rural regions building upon the findings contained in the New Rural Paradigm (OECD 2006). Recent updates and improvements in the OECD Regional Database have expanded time-coverage and added new indicators. Furthermore, advancements in the regional taxonomy allow us to examine with more precision the growth trends within rural regions. According to the OECD regional taxonomy OECD regions are classified into three types: urban, intermediate and rural (see Annex 1). The extended OECD regional taxonomy (Brezzi et. at, 2011) builds upon the OECD taxonomy and further classifies rural regions into two types: rural regions close to cities and rural remote regions (see Annex 2). The paper applies both typologies in the analysis given that the OECD taxonomy classifies a larger sample of regions than the extended OECD taxonomy:

- The OECD regional typology defines all 1725 OECD TL3 regions into three types of regions;

- In contrast the extended regional typology defines 1608 TL3 regions into four types. The extended typology does not currently classify TL3 regions from Australia, Estonia, Iceland, New Zealand, Korea and Slovenia. 
The time period where data are available for a number of indicators used in the analysis cover the years 1995-2010. The analysis is split into two time periods; the first covers the pre-crisis period and second the impact of the crisis. The purpose of splitting the analysis into two time periods is to discriminate between long term and structural effects with the effects of the 2008 global financial crisis, which can vary considerable among types of regions. The analysis compares both level and growth effects among types of regions. Our data are taken from the OECD Regional Database and our unit of analysis is Territorial Level 3 regions which correspond to small OECD regions.

\section{Settlement patterns among types of regions}

This section focuses on settlement patterns and surface area. It first compares the proportion of inhabitants living in urban, intermediate and rural regions in the year 1995 and then it compares this proportion to that observed in the year 2010 along with the surface breakdown in the three types of regions. It is noteworthy to mention that these calculations do not necessarily mirror the rates of urbanisation since the former are based on territories and the latter on urban settlements. The results are depicted in Table 1 and reveal that:

- More than half of the OECD population live in non-urban regions; in specific $25 \%$ live in rural regions, $28 \%$ in intermediate and the remaining $47 \%$ in urban regions.

- Despite the ongoing process of urbanisation, the share of population living in different types of regions in the OECD has remained fairly stable and unchanged over a 15 year period.

- In terms of the surface land, around $81 \%$ of the surface area is located in rural regions, $13 \%$ in intermediate and only $6 \%$ in urban.

Table 1. Population and surface area in OECD TL3 regions, OECD typology, 1995-2010

\begin{tabular}{lcccc|cc|}
\hline \multicolumn{5}{c}{ Population } & \multicolumn{2}{c|}{ Surface area } \\
\hline & 1995 & 2010 & 1995 & 2010 & \multicolumn{2}{c|}{2010} \\
& $503,159,342$ & $557,715,508$ & $47 \%$ & $47 \%$ & $2,028,283$ & $6 \%$ \\
\hline urban (PU) & $300,926,016$ & $326,519,611$ & $28 \%$ & $28 \%$ & $4,482,378$ & $13 \%$ \\
intermediate & $37,660,875$ & $297,856,762$ & $25 \%$ & $25 \%$ & $26,962,941$ & $81 \%$ \\
rural (PR) & $273,660,8)$ & share \\
total & $1,077,746,233$ & $1,182,091,881$ & $100 \%$ & $100 \%$ & $33,473,602$ & $100 \%$ \\
\hline
\end{tabular}

The analysis next replicates the calculations using the extended typology in Table 2, which contains a smaller sample of TL3 regions. According to these calculations, the great majority of rural dwellers live in rural regions close to cities, representing around $20 \%$ of the OECD total population and $6 \%$ live in remote rural regions.

Table 2. Population and surface area in OECD TL3 regions, OECD extended typology, 1995-2010

\begin{tabular}{lcccc|cc|}
\hline & \multicolumn{3}{c|}{ Population } & \multicolumn{2}{c|}{ Surface area } \\
\hline & \multicolumn{3}{c}{ value } & \multicolumn{2}{c|}{ share } & \multicolumn{2}{c|}{ value } & share \\
& 1995 & 2010 & 1995 & 2010 & 2010 \\
\hline urban (PU) & $463,570,544$ & $515,603,788$ & $46 \%$ & $47 \%$ & 1959857.9 & $8 \%$ \\
intermediate & $279,995,819$ & $300,424,412$ & $28 \%$ & $27 \%$ & 3098479.2 & $13 \%$ \\
PRC & $198,038,570$ & $220,221,909$ & $20 \%$ & $20 \%$ & 7087474.9 & $30 \%$ \\
PRR & $60,102,089$ & $61,737,753$ & $6 \%$ & $6 \%$ & 11636940 & $49 \%$ \\
total & $1,001,707,022$ & $1,097,987,862$ & $100 \%$ & $100 \%$ & $23,782,752$ & $100 \%$ \\
\hline
\end{tabular}

Note: PRC refers to predominantly rural regions close to a city and PRR to predominantly rural remote regions. 
In other words around $77 \%$ of the rural population live in rural regions close to cities; the remaining $13 \%$ is located in rural remote regions. In terms of the surface area, close to $50 \%$ of the total surface area in the OECD is contained in remote rural regions and $30 \%$ in rural regions close to cities. As with the regional typology, the proportion of population living in each type of region has remained fairly unchanged over a 15 year period.

\section{Level comparisons and characteristics of rural regions}

Urban and rural regions tend to differ in their socio-economic characteristics. In the economics literature, urban and rural regions are typically associated with core and periphery regions in the New Economic Geography core-periphery models (see Krugam 1991, or OECD 2009a for a literature review). In these models, periphery regions (or southern regions) are assumed to have an agricultural production technology tied to land with constant returns to scale and unskilled labour. In contrast core regions (or northern regions) are assumed to have a manufacturing production technology with increasing returns to scale and skilled labour. Although these assumptions have never been tested and confirmed empirically, equating rural with agricultural activities and in turn constant return to scale is questionable in many OECD rural regions. ${ }^{1}$ Nevertheless urban regions indeed tend to have higher agglomeration effects due to the presence of higher economic and population densities than rural regions. There is currently no evidence on understanding how big these agglomeration effects are, or what other socio-economic characteristics distinguish urban from rural regions.

This section advances in this task and compares a number of indicators among OECD types of regions. The selected list of indicators is driven by the availability of data at the level of TL3. Indicators are grouped into the following five broad categories:

- The first captures size and scale-effects; including GDP, population and employment.

- The second type measures agglomeration effects, through GDP density and population density.

- The third type measures labour market outcomes; including employment rates, unemployment rates, and participation rates.

- The fourth group captures overall performance and competitiveness of regions measuring GDP per capita and productivity (GDP per employee).

- The fifth group captures the inventive activity of regions measured by patent applications and patent intensity (patent applications per million).

The comparisons of indicators (in levels) are provided in Table 3 reporting both the average value and median value among the three types of regions considered in the OECD regional typology. The level comparisons show a number of well known regularities and characteristics among the different types of regions:

- Urban regions have a significantly larger economic base reflected by higher overall economic output and overall employment base. On average they produce five times more output than rural regions and more than twice than intermediate regions. The median output in urban regions tends to be four times higher than the median output in rural region for the year 2009.

1. The New Rural Paradigm Rural displays how OECD rural regions are no longer synonymous with agricultural activities. Many rural regions indeed depend on non-agricultural activities including among others tourism, and the tradable sector with extractive and manufacturing activities. 
- In terms of employment, urban regions also enjoy from larger scale effects and on average have three times more total employees in their labour force than rural regions and twice as much as intermediate regions.

- The largest difference however is present in the agglomeration effects: in urban regions they exceed the effects present in rural regions by a magnitude of $\mathbf{4 1}$ in terms of GDP density and by a magnitude of $\mathbf{3 2}$ in terms of population density on average. The median value is around $\mathbf{1 7}$ times higher for urban region in GDP density and 20 times for population density.

- They also enjoy from better labour market matching reflected by lower unemployment rates despite having lower rates of participation in the labour market and lower employment rates than urban and intermediate regions. Urban regions display on average lower unemployment rates $(8.1 \%)$ than rural regions $(8.5 \%)$. Employment and participation rates in contrast are higher in rural regions (around 1 full percentage point on average) than in urban and in intermediate regions. These combined trends suggest that labour market matching tends to be better, all things equal in urban regions than in rural ones. Notwithstanding this fact, rural regions appear to be quite successful in employing their workforce.

- Finally the inventive activity is more than ten times higher in urban regions than in rural regions according to total patent applications. In relative terms (patents per million) inventive activity in urban regions is two and a half times higher than in rural regions.

Table 3. Average and median levels in OECD TL3 regions, OECD typology, 2009

\begin{tabular}{|c|c|c|c|c|c|c|c|}
\hline & & \multicolumn{3}{|c|}{ average } & \multicolumn{3}{|c|}{ median } \\
\hline & & urban (PU) & intermediate & rural (PR) & urban (PU) & intermediate & rural (PR) \\
\hline \multirow{3}{*}{$\begin{array}{c}\text { size and scale } \\
\text { effects }\end{array}$} & GDP & 44,579 & 17,388 & 8,757 & 26,000 & 12,861 & 6,214 \\
\hline & population & $1,553,525$ & 720,794 & 328,036 & 876,705 & 502,689 & 184,491 \\
\hline & employment & 750,809 & 374,777 & 237,546 & 394,900 & 238,000 & 146,817 \\
\hline \multirow{2}{*}{$\begin{array}{l}\text { agglomeration } \\
\text { effects }\end{array}$} & GDP density & 61.2 & 4.3 & 1.5 & 19.0 & 3.2 & 1.1 \\
\hline & population density & 1224.2 & 144.7 & 37.5 & 492.9 & 127.4 & 25.0 \\
\hline \multirow{3}{*}{$\begin{array}{l}\text { labour market } \\
\text { outcomes }\end{array}$} & unemployment rate & 8.1 & 8.1 & 8.5 & 7.3 & 7.1 & 8.2 \\
\hline & employment rate & 66.6 & 66.5 & 67.6 & 66.7 & 66.2 & 67.7 \\
\hline & participation rate & 73.4 & 73.0 & 74.4 & 74.2 & 73.1 & 74.9 \\
\hline \multirow{2}{*}{$\begin{array}{c}\text { performance \& } \\
\text { competitiveness }\end{array}$} & GDP per capita & 30,390 & 23,740 & 21,196 & 29,562 & 23,946 & 22,144 \\
\hline & GDP per w orker & 72,136 & 59,319 & 54,391 & 69,714 & 60,116 & 55,580 \\
\hline \multirow{2}{*}{ inventive activity } & patent applications & 220 & 80 & 23 & 49 & 17 & 2 \\
\hline & patents per million & 110 & 71 & 45 & 68 & 43 & 22 \\
\hline
\end{tabular}

In sum, urban regions enjoy higher inventive activity, greater scale effects, even higher agglomeration benefits and better market matching than rural regions reflecting higher levels of GDP per capita and higher levels of productivity in urban regions vis-à-vis rural regions.

- In terms of GDP per capita, urban regions on average record per capita levels exceeding $40 \%$ of those by rural regions.

- Productivity in urban regions however is around $\mathbf{3 2 \%}$ higher than in rural regions. 
In other words the characteristics between rural and urban regions vary significantly. One can also say that rural regions are characterised by low density, long distances and lack of critical mass.

The level comparisons when using the extended OECD typology (Table 4) display an even larger gap between urban and remote rural regions in scale effects, agglomeration effects, labour market matching and patent intensity:

- Total GDP in urban region exceeds on average GDP in rural remote regions by a factor of $\mathbf{6}$; total employment is $\mathbf{5 . 5}$ times larger.

- GDP and population density, measured by GDP per square kilometre of surface area and population per square kilometre is $\mathbf{6 0}$ times and $\mathbf{5 4}$ times larger respectively in urban regions than in remote rural ones.

- Although the gap in unemployment rates is the same, remote rural regions enjoy even higher participation and employment rates than urban regions: more than three full percentages points.

- The total number of patent applications in urban regions is on average $\mathbf{3 4}$ times higher than in rural remote regions. In relation to its population (patent per million) they are three times higher.

Despite these differences between urban and remote rural regions, the gap in GDP per capita between the two is smaller than between urban and rural regions -- around $32 \%$ lower in remote rural regions while the gap in productivity remains around $32 \%$ lower for remote rural regions.

Table 4. Average and median levels in OECD TL3 regions, OECD typology, 2009

\begin{tabular}{|c|c|c|c|c|c|c|c|c|c|}
\hline & & \multicolumn{4}{|c|}{ average } & \multicolumn{4}{|c|}{ median } \\
\hline & & urban (PU) & intermediate & PRC & PRR & urban (PU) & intermediate & PRC & PRR \\
\hline \multirow{3}{*}{$\begin{array}{c}\text { size and scale } \\
\text { effects }\end{array}$} & GDP & 42,175 & 16,788 & 9,043 & 6,542 & 24,988 & 12,957 & 7,592 & 3,958 \\
\hline & population & $1,503,218$ & 718,719 & 488,297 & 156,298 & 858,915 & 524,963 & 335,860 & 77,757 \\
\hline & employment & 727,931 & 368,851 & 290,261 & 132,033 & 386,993 & 239,950 & 188,834 & 91,600 \\
\hline \multirow{2}{*}{$\begin{array}{c}\text { agglomeration } \\
\text { effects }\end{array}$} & GDP density & 60.2 & 4.1 & 1.7 & 1.0 & 18.7 & 3.4 & 1.3 & 0.6 \\
\hline & population density & 1175.0 & 146.3 & 52.5 & 21.7 & 488.8 & 133.2 & 45.2 & 9.7 \\
\hline \multirow{3}{*}{$\begin{array}{c}\text { labour market } \\
\text { outcomes }\end{array}$} & unemployment rate & 8.2 & 8.3 & 8.5 & 8.8 & 7.5 & 7.3 & 8.2 & 8.5 \\
\hline & employment rate & 66.5 & 66.0 & 66.1 & 70.0 & 66.7 & 65.7 & 66.2 & 70.0 \\
\hline & participation rate & 73.5 & 72.6 & 73.3 & 76.0 & 74.2 & 72.8 & 74.5 & 76.0 \\
\hline \multirow{2}{*}{$\begin{array}{l}\text { performance \& } \\
\text { competitiveness }\end{array}$} & GDP per capita & 30,576 & 23,772 & 19,719 & 23,076 & 29,640 & 24,314 & 21,267 & 23,129 \\
\hline & GDP per w orker & 73,055 & 60,153 & 53,864 & 55,460 & 70,826 & 60,608 & 55,472 & 58,073 \\
\hline \multirow{2}{*}{ inventive activity } & patent applications & 213 & 77 & 37 & 6 & 46 & 17 & 6 & 1 \\
\hline & patents per million & 109 & 73 & 57 & 33 & 66 & 42 & 25 & 20 \\
\hline
\end{tabular}

Note: PRC refers to predominantly rural regions close to a city and PRR to predominantly rural remote regions.

Comparing the level effects within rural regions (between remote rural regions and rural regions close to cities) reveals important differences:

- Remote rural regions have considerable lower critical mass; are even more sparsely populated and enjoy from lower agglomeration benefits, than rural regions close to cities

- In addition remote rural regions display higher unemployment rates (0.3 percentage points), higher rates of participation and employment rates ( 3 percentage points), higher levels of GDP 
per capita (17\% higher) and slightly higher levels of productivity than rural regions close to cities.

- Despite the lower inventive activity, in relation to its population rural remote regions trail the inventive activity in rural regions close to cities by less than half.

Despite the potential measurement bias, ${ }^{2}$ important differences appear in the characteristics of rural regions close to cities and rural remote regions requiring a differentiated rural policy capable of addressing these differences.

\section{Comparing growth patterns among types of regions.}

The next two sections compare growth patterns among types of regions in two time periods. The first considers the period prior to the global financial crisis and the second (in Section 4) captures the effects of the crisis. The period prior to the global financial crisis covers the years 1995 to 2007 given the available of data for most indicators in the Regional Database. Labour market indicators however are available from 1999-2007 in a wide number of European countries. Therefore the general rule we apply in the analysis is to include the first year were data are available from 1995 onwards and the latest year up to 2007, and compute the annual average growth rate -- or the annual average percentage point change -- over the entire period. The years 2007-2009 or in some regions up to 2010 capture the effects of the crisis. The analysis also reports the benchmark separately when using the OECD typology and the extended OECD typology given the different sample of regions in the two taxonomies. We compare the performances among types of OECD regions on average first and then within each OECD country among types of regions.

The first benchmark (Table 5) compares the growth rates in urban, intermediate and rural regions, among the same list of indicators used in the previous section over 1995-2007 and reveals:

- Urban regions on average grew slightly faster (2.74\%) in overall GDP than intermediate $(2.58 \%)$ and rural $(2.55 \%)$ regions.

- Growth in total population was also significantly higher in urban $(0.7 \%)$ than in intermediate $(0.47 \%)$ and more than twice $(0.27 \%)$ than in rural regions.

- The largest gains in unemployment rates and employment rates occurred in intermediate regions (-.32, and 0.47 percentage points respectively).

- The highest rate of growth in GDP per capita and in productivity occurred in rural regions (3\% and $1.46 \%$ respectively) over the 1995-2007 period compared to urban and intermediate regions.

- In terms of inventive activity, growth in urban region is the highest (7.56\%) in patent applications, closely followed by intermediate regions (7.32\%) and one a half percentage points higher than in rural regions (6.14\%). This gap however is reduced in terms of patent intensity (patents per million) where rural regions trail urban growth by less than one percentage point.

2. There is an inherent bias driven by the commuting patterns of dwellers living in rural regions close cities and working in the city underestimating GDP per capita in these types of rural regions. 
Table 5. Growth rates among OECD TL3 typology, 1995-2007

\begin{tabular}{|c|c|c|c|}
\hline & urban (PU) & intermediate & rural (PR) \\
\hline GDP & $2.74 \%$ & $2.58 \%$ & $2.55 \%$ \\
\hline population & $0.70 \%$ & $0.47 \%$ & $0 \%$ \\
\hline employment & $1.1 \%$ & $1.2 \%$ & $1.1 \%$ \\
\hline GDP density (pp) & 1.59 & 0.10 & 0.03 \\
\hline poplation density (pp) & 4.80 & 0.63 & 0.13 \\
\hline unemployment rate (pp) & -0.18 & -0.32 & -0.21 \\
\hline employment rate (pp) & 0.38 & 0.47 & 0.27 \\
\hline participation rate (pp) & 0.38 & 0.33 & 0.13 \\
\hline GDP per capita & $2.48 \%$ & $2.43 \%$ & $3 \%$ \\
\hline GDP per w orker & $1.33 \%$ & $1.16 \%$ & $1.46 \%$ \\
\hline patent applications* & $7.56 \%$ & $7.32 \%$ & $6.14 \%$ \\
\hline patents per million* & $7.06 \%$ & $6.99 \%$ & $6.28 \%$ \\
\hline
\end{tabular}

Note: * the growth rates correspond to the value of a four year moving average, given the yearly fluctuations in patent applications.

The extended typology allows for comparing the growth performance between rural remote regions and rural regions close to cities. Table 6 highlights import difference between the two:

- Rural regions close to a city are the most dynamic type of regions in terms of GDP per capita growth and productivity growth (3.08\% and 1.61\%) over 1995-2007 when compared to urban, intermediate and rural remote regions. Despite the presence of a potential measurement bias affecting GDP per capita in rural regions close to cities, the bias does not affect the growth figures unless commuting patterns change systematically over time.

- Rural remote regions record the second highest growth rate in GDP per capita among types of regions, despite having the lowest productivity growth on average.

- In terms of population growth, rural regions close to cities are important attractors of population and rural remote regions suffer population declines. Rural regions close to cities recorded the second highest population growth $(0.55 \%)$ among the four types of regions after urban regions $(0.69 \%)$. Remote rural regions in contrast are the only types of regions suffering from population declines, on average annually loosing $0.08 \%$ of its population.

- In terms of inventive activity in absolute terms (patent applications), rural regions close to cities trail the urban growth by approximately half of a percentage point. Growth in rural remote regions in patent application is significantly lower. In relation to its population, the gap in the growth of patent intensity is further reduced. Rural regions close to cities slightly trail the rate of growth of urban regions -- by less than two tenths of a percentage point, and rural remote regions trail urban growth by one percentage point. The fact that intermediate regions display a slightly higher rate of growth than urban regions (in contrast to Table 5) is due to the different sample of regions among both typologies. 
Table 6. Growth rates among OECD TL3 extended typology, 1995-2007

\begin{tabular}{lcccc}
\hline & PU & N & PRC & PRR \\
\hline GDP & $2.71 \%$ & $2.52 \%$ & $2.59 \%$ & $2.31 \%$ \\
population & $0.69 \%$ & $0.44 \%$ & $0.55 \%$ & $-0.08 \%$ \\
GDP density (pp) & 1.55 & 0.09 & 0.03 & 0.02 \\
\hline employment & $1.11 \%$ & $1.20 \%$ & $1.02 \%$ & $1.18 \%$ \\
poplation density (pp) & 4.90 & 0.56 & 0.24 & 0.01 \\
\hline unemployment rate (pp) & -0.17 & -0.33 & -0.22 & -0.19 \\
employment rate (pp) & 0.39 & 0.47 & 0.14 & 0.52 \\
participation rate (pp) & 0.38 & 0.32 & 0.03 & 0.43 \\
\hline GDP per capita & $2.47 \%$ & $2.40 \%$ & $3.08 \%$ & $2.72 \%$ \\
GDP per w orker & $1.28 \%$ & $1.14 \%$ & $1.61 \%$ & $1.02 \%$ \\
\hline patent applications & $7.31 \%$ & $7.20 \%$ & $6.76 \%$ & $5.21 \%$ \\
patents per million* & $6.82 \%$ & $6.89 \%$ & $6.64 \%$ & $5.82 \%$ \\
\hline
\end{tabular}

Note: * given the yearly fluctuations in patent applications the growth rates correspond the value of a four year moving average

\section{Volatility in growth performance}

Rural regions are more volatile in their growth performance than urban and intermediate regions, both in GDP per capita and in productivity growth over 1995-2007. Despite their higher average and median growth rate, rural performance is more volatile both on the upper end of the distribution and on the lower end. This suggests that on the one hand, rural economies have a strong growth potential and on the other hand they are also more vulnerable due to their thinner and less diversified economic base making them less capable to buffer external shocks and fluctuations in commodity prices.

Figure 1. Distribution of GDP per capita and productivity growth by TL3 typology, 1995-2007

GDP per capita growth

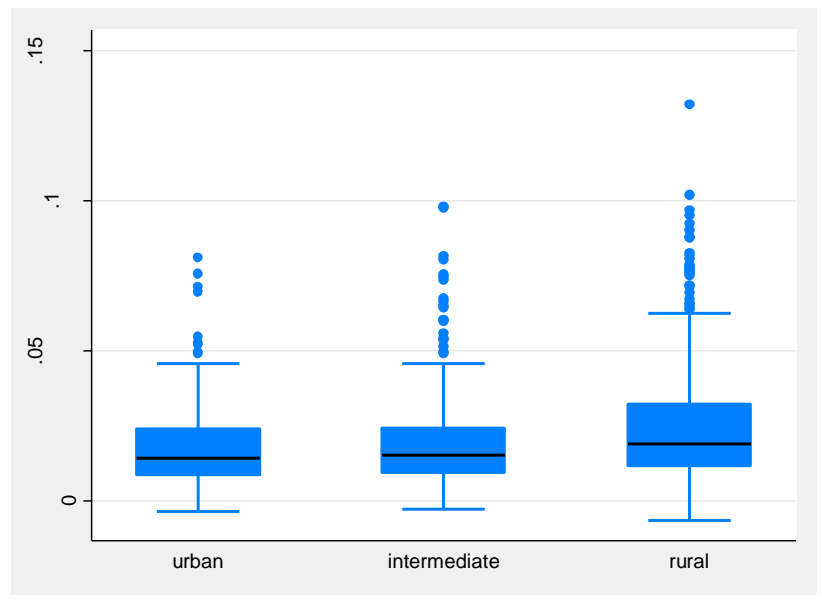

Productivity (GDP per worker)

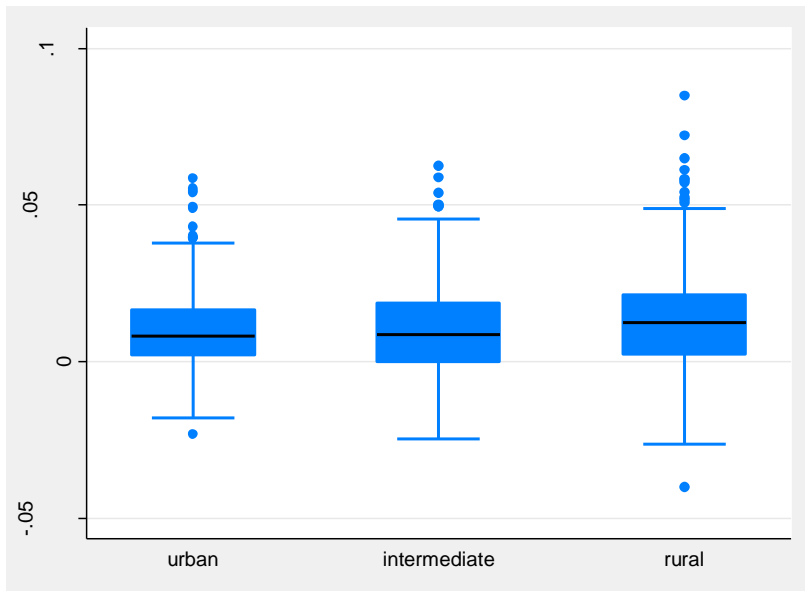


The volatility in GDP per capita growth appears to be higher in rural regions close to cities than in rural remote regions (Figure 2). This result is driven by the interdependence of these types of regions to their larger city conurbations. In addition the ability of these regions to cope with the strong population influx varies. In terms of productivity growth, rural remote regions experience the second highest median value and the lowest $25^{\text {th }}$ percentile value amongst all types of regions revealing the vulnerability of remote rural regions.

Figure 2. Distribution of GDP per capita and productivity growth by TL3 extended typology, 1995-2007

GDP per capita growth

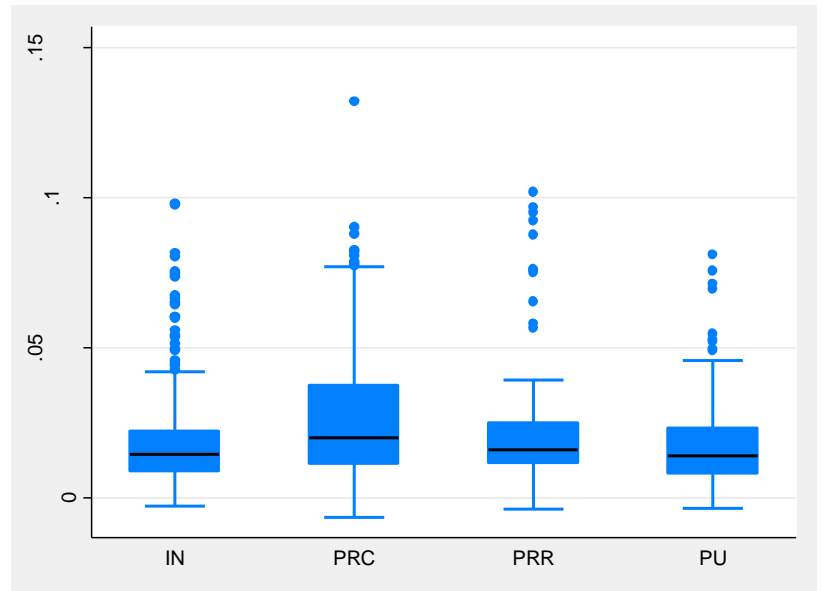

Productivity (GDP per worker)

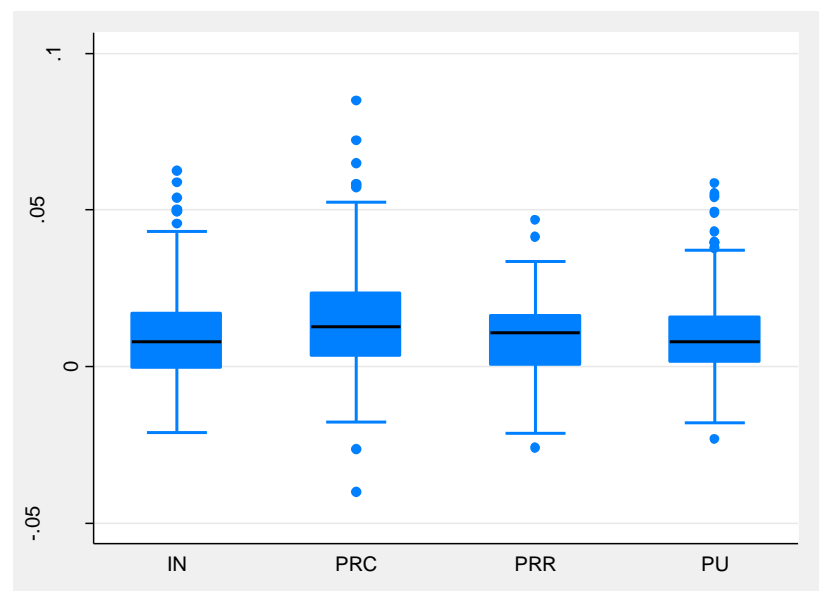

\section{Growth rates within countries}

The benchmark comparing performances by type of regions is broken down by country in Tables 7 and 8 helping understand how the different growth dynamics varies within countries. In 9 out of 22 OECD countries considered -- representing 40\% -- rural regions recorded the fastest pace of growth in GDP per capita growth over the period 1995-2007 relative to intermediate and urban regions. These countries include Austria, Germany, Ireland, Italy, Japan, Korea, Portugal, Slovenia and Turkey. In a smaller number of countries ( 8 out of the 22 considered) rural regions recorded the slowest pace of growth among types of regions on average. 
Table 7. Growth rates among OECD TL3 typology within countries, 1995-2007

\begin{tabular}{lccc}
\hline & urban (PU) & intermediate & rural (PR) \\
\hline Austria & $1.56 \%$ & $2.22 \%$ & $2.22 \%$ \\
Belgium & $2.08 \%$ & $1.76 \%$ & $1.42 \%$ \\
Czech Republic & $5.36 \%$ & $2.45 \%$ & $3.05 \%$ \\
\hline France & $2.08 \%$ & $1.24 \%$ & $1.05 \%$ \\
Germany & $1.42 \%$ & $1.69 \%$ & $1.96 \%$ \\
Greece & $3.30 \%$ & $1.77 \%$ & $2.30 \%$ \\
Hungary & $5.23 \%$ & $3.22 \%$ & $1.74 \%$ \\
Ireland & $1.49 \%$ &. & $4.62 \%$ \\
Italy & $1.98 \%$ & $2.21 \%$ & $2.66 \%$ \\
\hline Japan & $1.08 \%$ & $1.32 \%$ & $1.44 \%$ \\
\hline Korea & $3.66 \%$ & $2.59 \%$ & $4.98 \%$ \\
\hline Netherlands & $2.32 \%$ & $2.04 \%$ &. \\
New Zealand & $1.30 \%$ & $2.88 \%$ &. \\
Norw ay & $1.58 \%$ & $1.72 \%$ & $1.27 \%$ \\
\hline Poland & $3.77 \%$ & $4.09 \%$ & $3.95 \%$ \\
\hline Portugal & $2.00 \%$ & $1.91 \%$ & $2.30 \%$ \\
\hline Slovak Republic & $5.91 \%$ & $4.54 \%$ & $4.13 \%$ \\
\hline Slovenia &. & $3.64 \%$ & $4.04 \%$ \\
\hline Spain & $2.90 \%$ & $2.61 \%$ & $2.53 \%$ \\
\hline Sw eden & $3.38 \%$ & $3.01 \%$ & $2.49 \%$ \\
\hline Turkey & $4.95 \%$ & $5.07 \%$ & $6.56 \%$ \\
\hline United Kingdom & $2.73 \%$ & $2.38 \%$ & $2.26 \%$ \\
\hline & & & \\
\hline
\end{tabular}

Even through predominantly rural regions close to cities are on average the most dynamic group of regions, comparisons within countries reveal a heterogonous picture. Amongst the 14 OECD countries considered containing rural regions close to cities and rural remote regions and where GDP data are available, in half of them rural regions close to cities recorded a faster rate of growth in GDP per capita on average than remote rural regions. In the remaining half, remote rural regions outperformed the pace of grow of rural regions close to a city. In absolute terms in four OECD countries (Austria, Germany, Ireland and Norway) rural regions close to cities recorded the fastest pace of GDP per capita growth amongst the four types of regions, and in Italy, Portugal, Turkey and the United Kingdom remote rural regions were the most dynamic group. 
Table 8. Growth rates among OECD TL3 extended typology within countries, 1995-2007

\begin{tabular}{lcccc}
\hline & urban (PU) & intermediate & rural close to city & rural remote \\
\hline Austria & $1.56 \%$ & $2.22 \%$ & $2.36 \%$ & $1.92 \%$ \\
Belgium & $2.08 \%$ & $1.76 \%$ & $1.42 \%$ &. \\
Czech Republic & $5.36 \%$ & $2.45 \%$ & $3.05 \%$ &. \\
\hline France & $2.08 \%$ & $1.24 \%$ & $0.94 \%$ & $1.24 \%$ \\
Germany & $1.42 \%$ & $1.69 \%$ & $1.96 \%$ &. \\
Greece & $3.30 \%$ & $1.77 \%$ & $2.55 \%$ & $2.27 \%$ \\
Hungary & $5.23 \%$ & $3.22 \%$ & $1.76 \%$ & $1.72 \%$ \\
Ireland & $1.49 \%$ &. & $5.28 \%$ & $3.74 \%$ \\
Italy & $1.98 \%$ & $2.21 \%$ & $2.23 \%$ & $3.14 \%$ \\
\hline Japan & $1.06 \%$ & $1.32 \%$ & $1.12 \%$ & $1.65 \%$ \\
Netherlands & $2.32 \%$ & $2.04 \%$ &. &. \\
\hline Norw ay & $1.58 \%$ & $1.72 \%$ & $1.83 \%$ & $1.23 \%$ \\
Poland & $3.77 \%$ & $4.09 \%$ & $3.96 \%$ & $3.65 \%$ \\
\hline Portugal & $2.00 \%$ & $1.91 \%$ & $1.77 \%$ & $2.43 \%$ \\
Slovak Republic & $5.91 \%$ & $4.54 \%$ & $4.13 \%$ &. \\
\hline Spain & $2.90 \%$ & $2.61 \%$ & $2.42 \%$ & $2.64 \%$ \\
Sw eden & $3.38 \%$ & $3.01 \%$ & $2.55 \%$ & $2.44 \%$ \\
\hline Turkey & $4.95 \%$ & $5.07 \%$ & $6.31 \%$ & $7.25 \%$ \\
\hline United Kingdom & $2.73 \%$ & $2.38 \%$ & $1.65 \%$ & $3.02 \%$ \\
\hline
\end{tabular}

\section{Graphs of convergence}

Rural regions appear to have entered into a process of convergence. The dynamic performance of rural regions is primarily driven by rural regions with below average levels of GDP per capita (Figure 3). Rural regions with growth rates above $3.5 \%$ are primarily to be found in regions with below average initial GDP per capita. Rural regions with above rural average levels of GDP per capita appear to be growing more slowly.

Figure 3. Growth trends in rural regions, 1995-2007

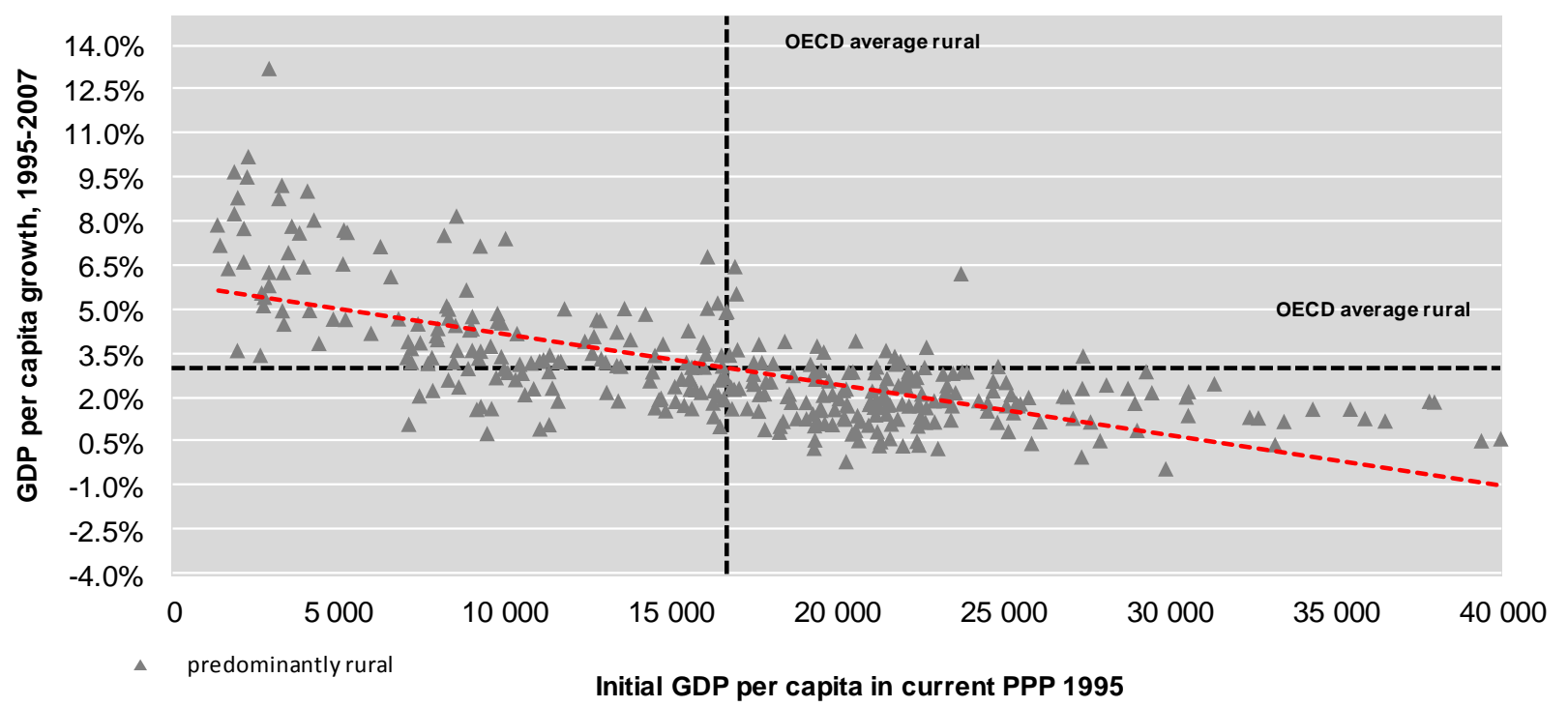


Intermediate regions are also experiencing a process of convergence between 1995 and 2007, characterised by regions with lower levels of initial GDP per capita recording higher growth rates. It is interesting to observe that among rural and intermediate regions there are no regions with high growth rates and high per capita incomes. These regions are only present in the urban group (Figure 5) with a more scattered picture displaying forces of convergence and forces of agglomeration.

Figure 4. Growth trends in intermediate regions, 1995-2007

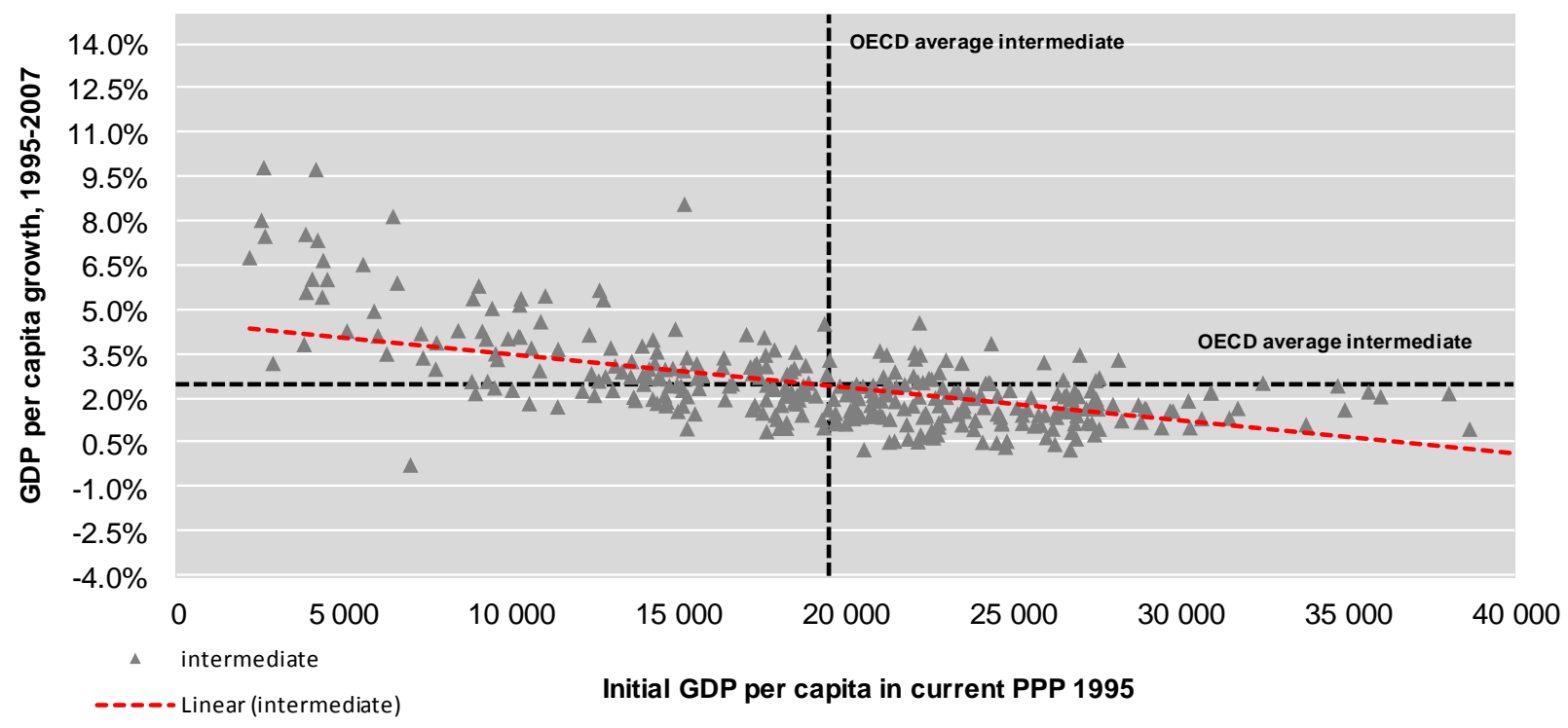

Figure 5. Growth trends in urban regions, 1995-2007

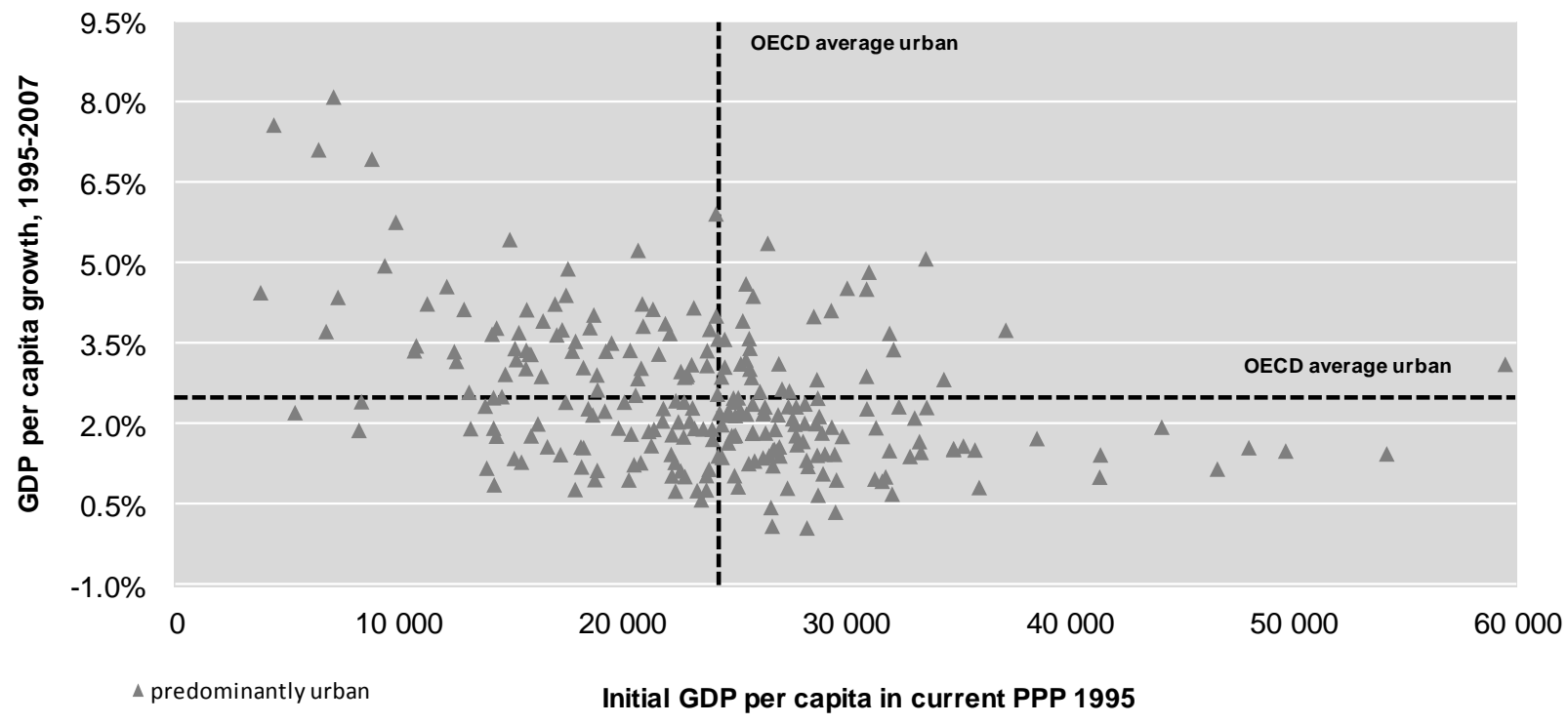


The dynamic performance of rural regions driving forces of convergence could in principle be driven by population declines. Similarly the trend of convergence in intermediate regions could also be driven by these effects. To analyse this, we graph the relationship between GDP per capita growth and population growth among the four categories of region. The graphs allow us to determine whether a statistical pattern is present between the two variables indicating for example whether high growth in GDP per capita is associated with population decline.

Figure 6. GDP per capita growth and population growth in OECD, 1995-2007 extended typology
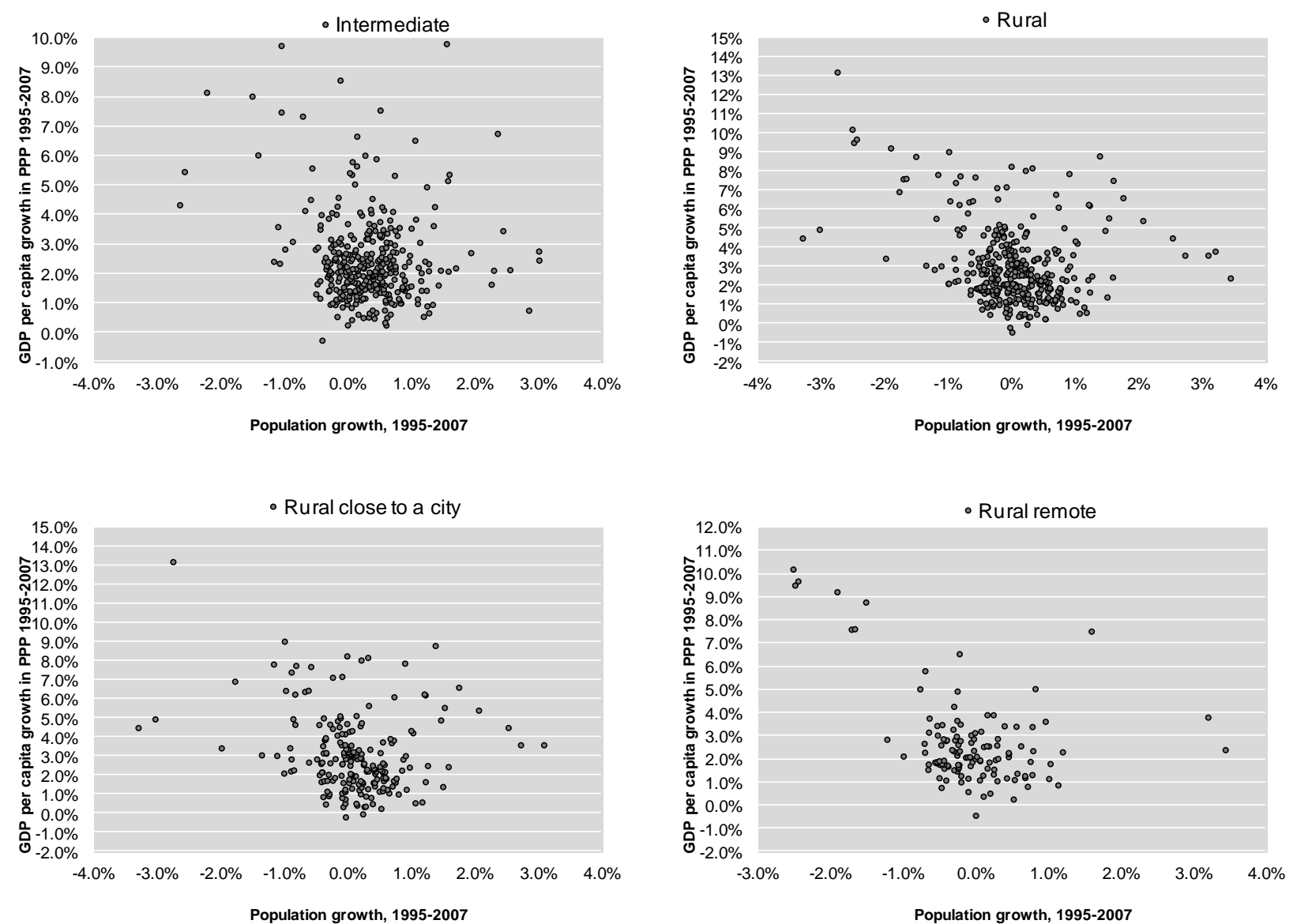

The graphs do not display a clear statistical pattern; rather they display a mixed and heterogeneous picture indicating that high growth rates in GPD per capita are driven equally by regions experiencing population increase and population declines and not necessarily due to denominator effects in the latter.

This result is particularly relevant for rural remote regions which are on average experiencing population decline. The patterns in these type of regions is equally heterogeneous with the exception of a group of seven outlier regions characterised with per capital growth rates above $7 \%$ and population decline below $1 \%$. In these regions, high GDP per capita growth appears to be driven by migration effects and population declines. 


\section{Performance during the crisis period}

The last section measures the effects of the global financial crisis among types of regions. We first measure the differentiated impact among three types of regions - urban, intermediate and rural regions and then among four types using the extended OECD typology and observing whether rural regions close to cities or rural remote regions have different effects. We measure the effects on GDP, GDP per capita, employment and unemployment rates. The period in the analysis covers the years 2007-2009 or in some indicators/regions up to 2010 due to availability of data. We measure the effects annually.

Table 9 reveals an interesting pattern; urban regions on average suffered the biggest impact during the crisis in terms of total output, GDP per-capita and employment rates. In terms of unemployment rates rural regions have suffered the largest impact. The result come to no surprise given the stronger links and interdependence of urban regions to global and international markets as well as their higher specialisation in financial services, becoming therefore more vulnerable to the trade shock and the financial services meltdown. Those rural regions specialised in natural resource activities have also been able to weather the effects of the crisis better due to the strong demand of natural resources by developing countries. Nevertheless their smaller economic base makes them more vulnerable to the economic shock and ability to absorb unemployed workers into other economic activities.

Table 9. Effects of the crisis among types of OECD regions, OECD typology 2007-2009

\begin{tabular}{lccc}
\hline & urban (PU) & intermediate & rural (PR) \\
\hline GDP & $-1.947 \%$ & $-1.808 \%$ & $-1.490 \%$ \\
unemployment rate $(\mathrm{pp})$ & 0.89 & 0.89 & 1.12 \\
employment rate $(\mathrm{pp})$ & -0.42 & -0.31 & -0.39 \\
GDP per capita & $-2.52 \%$ & $-2.26 \%$ & $-1.65 \%$ \\
\hline
\end{tabular}

Comparing the effects of the crisis in four types of regions according to the extended typology reveals that remote rural regions have been severely hit by the effects of the crisis (Table 10). These types of regions suffered the second largest absolute decline in GDP, the largest decline in unemployment rates and the largest decline in employment rates. Comparing the effects of the crisis between remote rural regions with rural regions close to cities reveals a much stronger impact of the crisis in remote rural regions in all of the four indicators considered.

Table 10. Effects of the crisis among types of OECD regions, extended OECD typology 2007-2009

\begin{tabular}{lcccc}
\hline & urban (PU) & intermediate & PRC & PRR \\
\hline GDP & $-2.091 \%$ & $-1.882 \%$ & $-1.235 \%$ & $-1.989 \%$ \\
unemployment rate (pp) & 0.91 & 0.90 & 1.05 & 1.32 \\
employment rate (pp) & -0.446 & -0.302 & -0.449 & -0.453 \\
GDP per capita & $-2.67 \%$ & $-2.33 \%$ & $-1.42 \%$ & $-2.16 \%$ \\
\hline
\end{tabular}

Despite the larger effects of the crisis in urban regions in GDP per capita, these average effects are driven by few large urban regions with high incomes severely hit by the crisis. Figure 7 maps the level of GDP per capita in 2007 on the X-axis with the level in 2009 in the Y-axis. The distribution in urban and intermediate regions appears to be more compressed around the 45 degree line -- except for regions with high GDP per capita - than for rural regions close to cities and rural remote regions. 
Figure 7. Effects of the crisis in GDP per capita in OECD TL3 regions, extended typology, 2007-2009
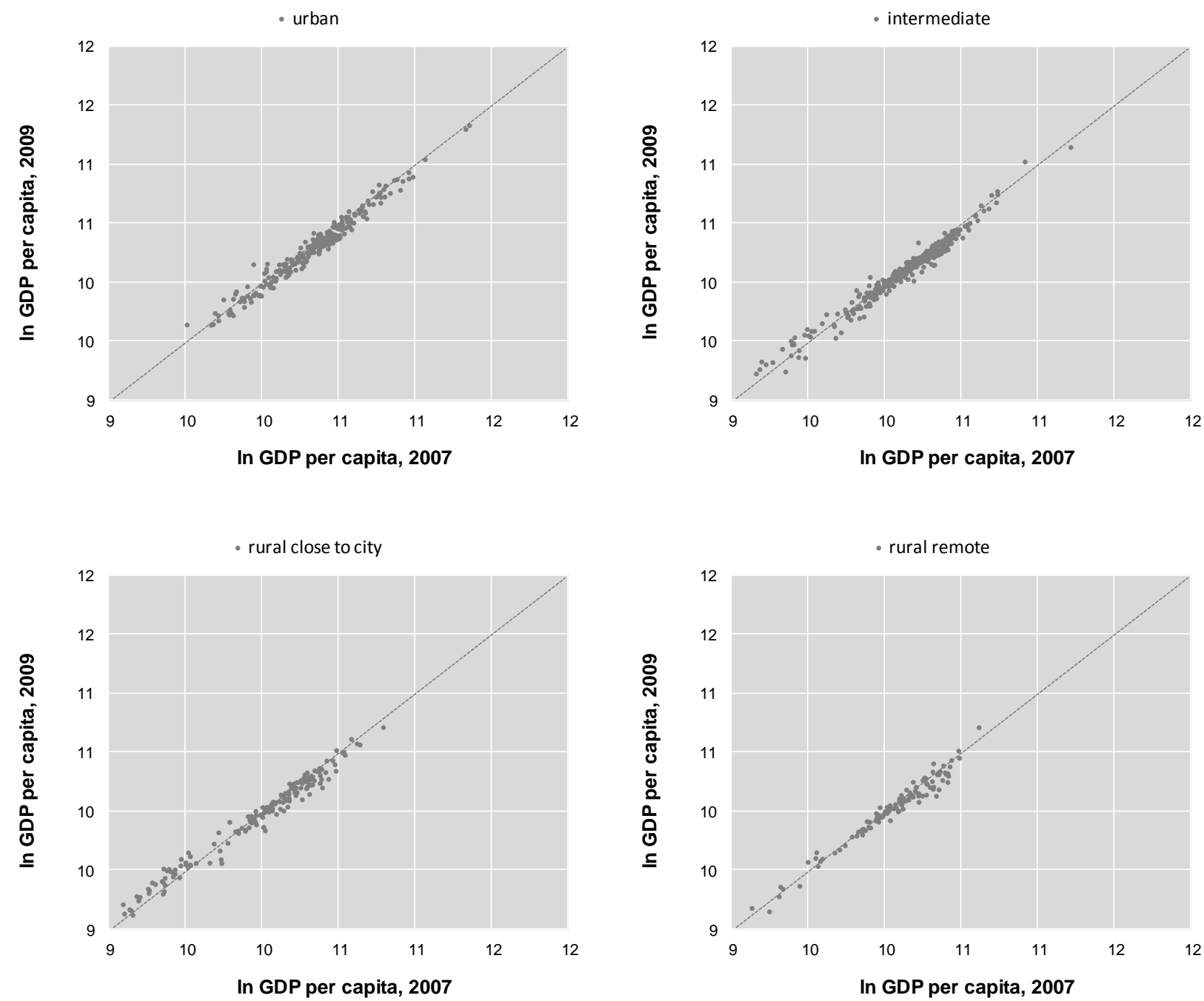

Similarly when comparing the distribution of unemployment rates in 2007 and 2009 among types of regions, we also observe a more compressed distribution for urban and intermediate regions as opposed to rural regions close to cities and especially remote rural regions (Figure 8). 
Figure 8. Effects of the crisis in unemployment rate in OECD TL3 regions, extended typology, 2007-2009
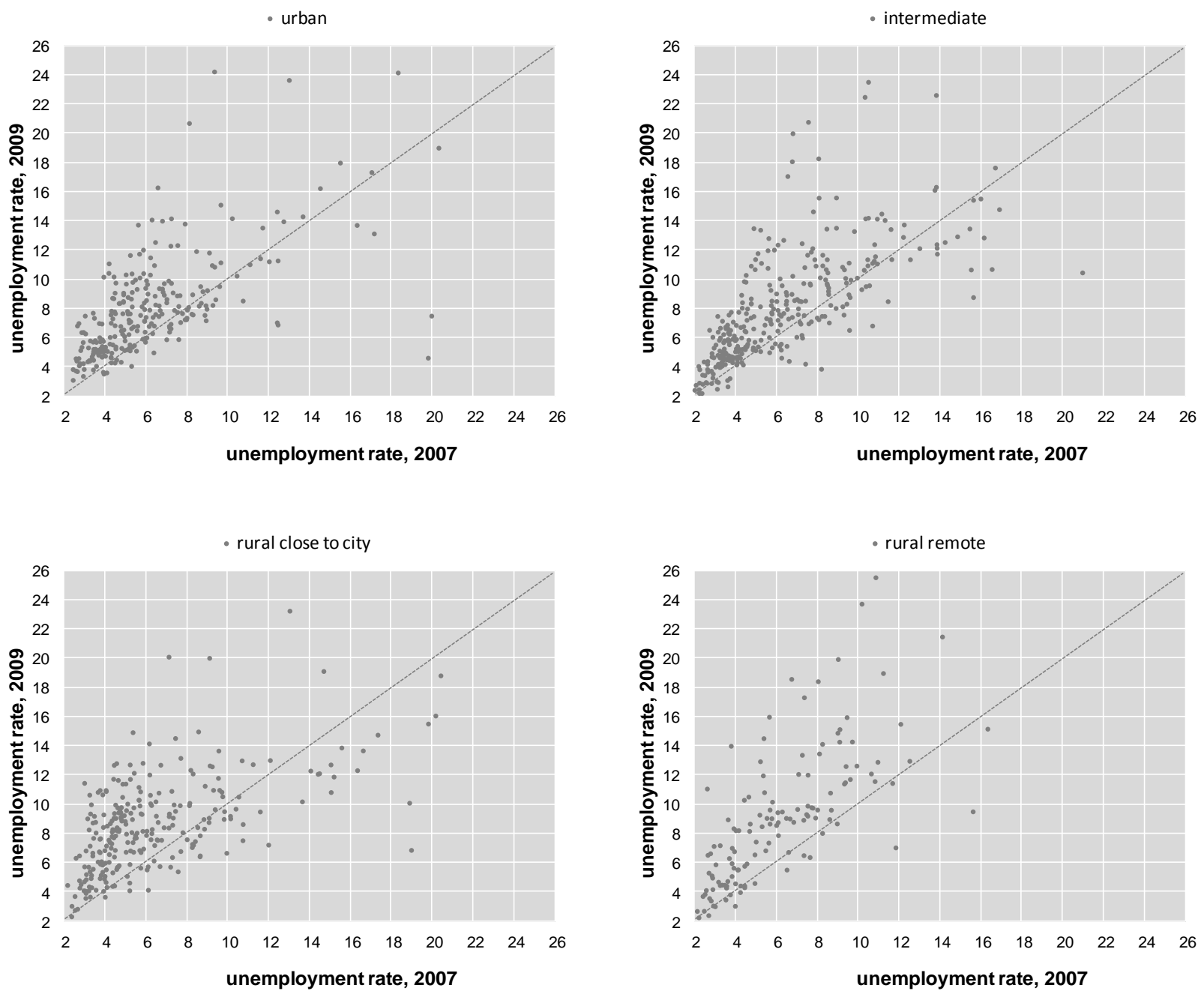

The analysis reveals that, although on average, the effects of the crisis appear to be more severe in urban regions; when comparing the distributions it emerges that these effects are driven by few regions. Rural regions appear to be more vulnerable to the effects of the crisis both in terms of GDP per capita and unemployment rates. Amongst rural regions, remote rural regions are more vulnerable to the crisis. In other words, the effects of the crisis will have stronger medium and long terms effects in rural regions, especially within remote rural regions. 


\section{Conclusions}

The analysis reveals stark differences between rural and urban regions and between rural regions close to cities and rural remote regions which suggests the need for a differentiated rural policy to address distinct challenges:

- All rural regions are characterised by low density, long distances and lack of critical mass.

- Remote rural regions have considerable lower critical mass than rural regions close to cities, they are even more sparsely populated, enjoy lower agglomeration benefits and inventive activities, have higher unemployment rates, higher rates of participation and higher employment rates. In addition rural regions close to cities are important attractors of population in contrast to remote rural regions suffering from a population decline. Proximity to urban regions can give these rural regions access to urban goods and services that are not available locally. 


\section{REFERENCES}

Brezzi M., L. Dijkstra and V. Ruiz (2011), "Extended Regional Typology: The Economic Performance of Remote Rural Regions”, OECD Regional Development Working Papers, 2011/06, OECD Publishing.

Krugman, P. (1991), "Increasing Returns and Economic Geography", The Journal of Political Economy, Vol. 99, No.3, pp. 483-99.

Krugman, Paul. 1996. Making Sense of the Competitiveness Debate. Oxford Review of Economic Policy. 12 pp. 17-35.

OECD (2006), The New Rural Paradigm in OECD countries, OECD Publishing, Paris

OECD (2009a), How Regions Grow: Trends and Analysis, OECD Publishing, Paris

OECD (2009b), Regions Matter: Economic Recovery, Innovation and Sustainable Growth, OECD Publishing, Paris

OECD (2012), Promoting Growth in all Types of Regions, OECD Publishing, Paris 


\section{ANNEX 1. OECD REGIONAL TYPOLOGY}

In any analytical study conducted at sub-national level, defining the territorial unit is of prime importance, as the word region can mean very different things both within and among countries. In order to have a measure that is comparable, the OECD has developed a regional typology for classifying regions within each member country.

The classification is based on two territorial levels. The higher level (Territorial Level 2 - TL2) consists of 335 large regions, while the lower level (Territorial Level 3 - TL3) is composed of 1679 small regions. All the regions are defined within national borders and in most cases correspond to administrative regions. Each TL3 region is contained within a TL2 region.

This classification - which, for European countries, is largely consistent with the Eurostat classification - helps to compare regions at the same territorial level. Indeed these two levels, which are officially established and relatively stable in all member countries, are used as a framework for implementing regional policies in most countries. In Slovenia TL3 regions corresponds to12 statistical regions.

The OECD typology classifies TL3 regions as predominantly urban, predominantly rural and intermediate. This typology, based on the percentage of regional population living in rural or urban communities, allows for meaningful comparisons among regions of the same type and level. The OECD regional typology is based on three criteria. The first identifies rural communities (kommun in Sweden) according to population density. A community is defined as rural if its population density is below 150 inhabitants per square kilometre (500 inhabitants for Japan to account for the fact that its national population exceeds 300 inhabitants per square kilometre). The second criterion classifies regions according to the percentage of population living in rural communities. Thus, a TL3 region is classified as:

- predominantly rural (rural), if more than $50 \%$ of its population lives in rural communities.

- $\quad$ predominantly urban (urban), if less than $15 \%$ of the population lives in rural communities.

- intermediate, if the share of population living in rural communities is between $15 \%$ and $50 \%$.

The third criterion is based on the size of the urban centres. Accordingly:

- A region that would be classified as rural on the basis of the general rule is classified as intermediate if it has an urban centre of more than 200000 inhabitants (500 000 for Japan) representing no less than $25 \%$ of the regional population.

- A region that would be classified as intermediate on the basis of the general rule is classified as predominantly urban if it has a urban centre of more than 500000 inhabitants (1 000000 for Japan) representing no less than $25 \%$ of the regional population. 


\section{ANNEX 2 OECD EXTENDED TYPOLOGY}

To account for differences among rural and urban regions, the OECD established a regional typology, classifying TL3 regions as predominantly urban (PU), intermediate (IN) or predominantly rural (PR). This typology proved to be a meaningful approach to explaining regional differences in economic and labour market performance. However, it did not take into account the presence of "agglomeration forces" or additional impacts of neighbouring regions. In addition remote rural regions typically face a different set of problems than rural regions close to a city, where a wider range of services and opportunities are commonly available.

The extended regional typology tries to discriminate between these forces and is based on a methodology proposed by the Directorate General for Regional Policy of the European Commission which refines the current typology by including a criterion on the accessibility to urban centres. This allows distinguishing between remote rural regions and rural regions close to a city in terms of declining and ageing population, level of productivity and unemployment; and similarly it also distinguishes between intermediate regions close to cities and remote intermediate cities.

Figure A2.1 summaries the methodology applied to derived the extended typology in the following steps:

Regions are classified as predominantly urban (PU), intermediate (IN) or predominantly rural (PR) based on the share of population living in local rural areas within each region and size of the urban centres contained in the TL3 regions. A region previously classified as PR (IN), becomes IN (PU) if it contains an urban centre with at least 200000 (500 000) inhabitants representing 25\% of the regional population. These three categories are known as the OECD regional typology.

In a second step, the OECD regional typology is extended by considering the driving time of at least $50 \%$ of the regional population to the closest centre of more than 50000 inhabitants. This only applies to the IN and PR categories, since by definition the PU regions include highly populated localities. The result is a typology containing five categories: PU, INC, INR, PRC, and PRR. 
Figure A2.1. Methodology employed in the extended typology

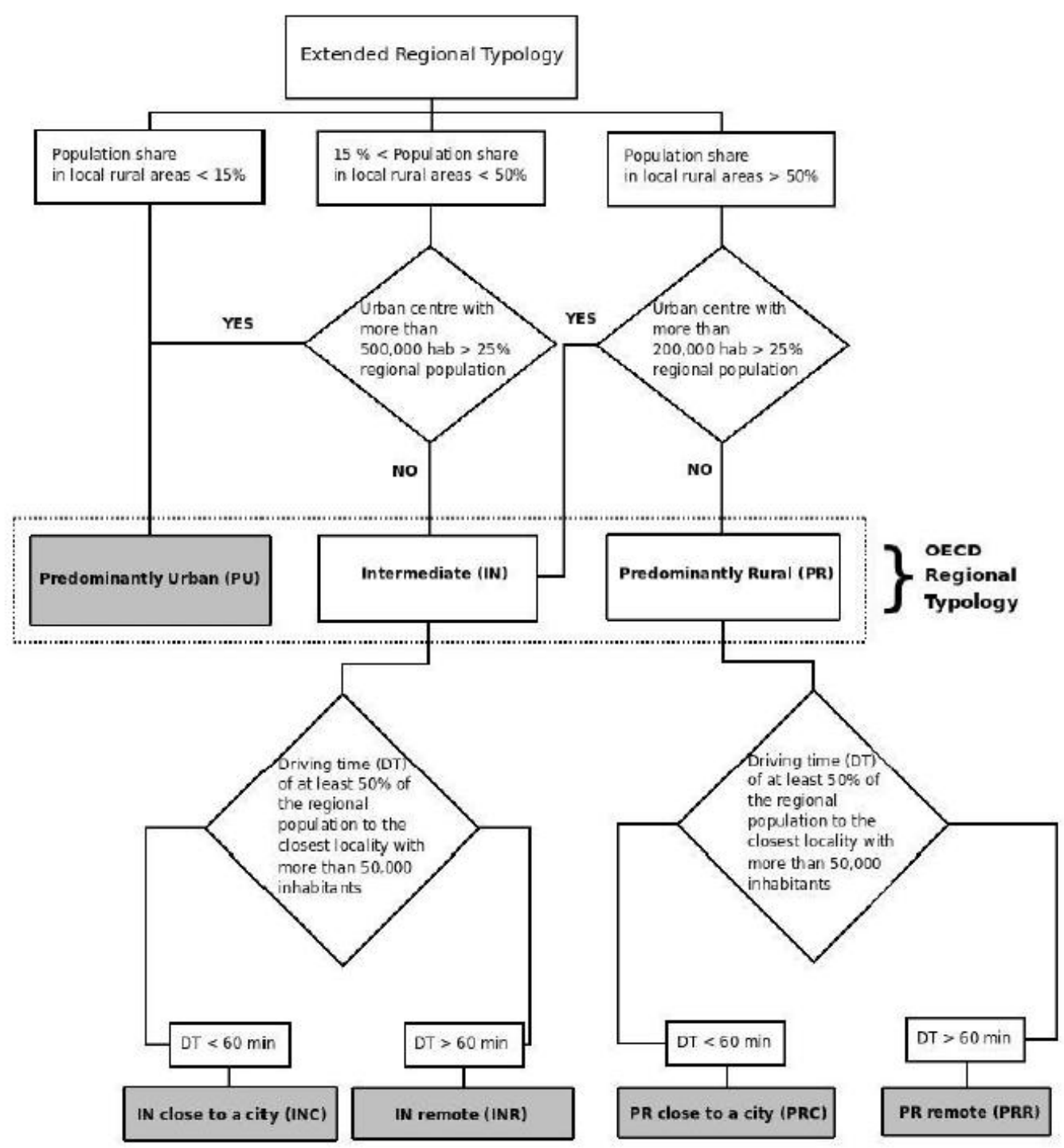

Source: Brezzi et. al, (2011), Extended Regional Typology: The Economic Performance of Remote Rural Regions", OECD Regional Development Working Papers, 2011/06, OECD Publishing, Paris. 